Fecha de recepción: octubre 2019 Fecha de aceptación: diciembre 2019 Versión final: diciembre 2021

\section{El alcance de la gastronomía mexicana en otras fronteras a través del diseño gráfico por el medio de la Web}

Amalia García Hernández ${ }^{1}$, Irma Lucía

Gutiérrez Cruz ${ }^{2}$ y Eva Guadalupe

Osuna Ruiz ${ }^{3}$

\begin{abstract}
Resumen: La gastronomía es "el arte culinario", donde más allá de los ingredientes, técnicas y métodos de sus recetas llevan consigo la evolución histórica y su significado cultural de la región donde los sabores, colores, ingredientes, son algo así como el vínculo del ser humano con su alimentación. En la cultura mexicana se encuentra una gran variedad de platillos regionales que se han mantenido a través del tiempo, recetas de la época prehispánica que hasta el día de hoy se mantienen en el pueblo de México, que con el paso del tiempo se han modificado debido a una falta de registro, pero no por eso pierde su gran valor cultural, pues a nivel mundial se puede escuchar hablar de ella. Visualizar los alcances que tendrá un platillo de comida en su máxima representación gráfica digital donde a través del color, las formas, la fotografía y la composición se pueda llevar a distintos sitios por medio del internet, donde miles de personas de todo el mundo que navegan en la Web atravesarán fronteras descubriendo la gastronomía de una región, llevando consigo no solo el impacto visual de la pieza de diseño sino mostrando la riqueza cultural de México.
\end{abstract}

Palabras clave: México - Diseño Gráfico - Web - Fotografía - Cultura - Fronteras - Gastronomía.

[Resúmenes en inglés y portugués en la página 136]

(1) Amalia García Hernández: Maestra en Mercadotecnia, con Diplomado de registro de marcas y patentes. Docente de tiempo completo en el Centro Universitario de Arte Arquitectura y Diseño, perfil PRODEP. Integrante del Cuerpo Académico en consolidación "Procesos de Comunicación y Educación Superior" (UDG-CA-790) profesora de la Licenciatura en Diseño para la Comunicación Gráfica, imparto la materia de Diseño VI -Campaña-. Mail: amaliaa72@yahoo.com.mx

(2) Irma Lucía Gutiérrez Cruz: Maestra en Tecnologías para el aprendizaje, Doctora en Arquitectura, Diseño y Urbanismo. Docente en la Lic. en Diseño para la Comunicación Gráfica, del Centro Universitario de Arte, Arquitectura y Diseño, Universidad de Guadalajara; perfil PROMEP y miembro del Cuerpo Académico "Procesos de la Comunicación y Educación Superior” UDG-CA-790. Coordinadora de Lic. en Diseño para la Comunicación Gráfica. Mail: lucia.gutierrez@cuaad.udg.mx 
${ }^{(3)}$ Eva Guadalupe Osuna Ruiz: Maestra en Planeación de la Educación Superior y Doctorante en Gestión de la Educación Superior. Profesor docente con perfil PRODEP, miembro del Cuerpo Académico en consolidación "Procesos de la Comunicación y Educación Superior" UDG-CA-790. Imparte el curso de Tesis I en la Lic. en Diseño para la Comunicación Gráfica. Miembro del núcleo académico básico de la Maestría en Gestión y Desarrollo Cultural. Mail: eva.osuna@cuaad.udg.mx

\section{Introducción}

En la actualidad el uso de la Web presenta grandes oportunidades para conocer cada parte del mundo, inclusive de los resultados se pueden obtener detalles de la búsqueda, todo dependerá de la forma en que se realice. El propósito de la presente investigación es obtener información de lo que sucede en otras fronteras, desde su cultura, sus costumbres y cualquier otra actividad, la información deberá ser factible y se deberá lograr la decodificación de la misma, es por ello de la importancia de la aplicación del diseño gráfico y la fotografía en las piezas digitales ya que estas siempre tendrán como objetivo un mensaje al usuario del sitio, en este capítulo se aborda el alcance de la gastronomía mexicana en otras fronteras a través del diseño gráfico y la fotografía por el medio de la Web.

La gastronomía es el estudio de la relación que existe entre cultura y alimento, no siendo suficiente un buen platillo o un excelente cocinero sino todo lo que se encuentra detrás como todos los elementos culturales, en donde el eje central es la comida, aquello que alimente al ser humano en el lugar del mundo en donde se encuentre, es aquí una representación clara de la cultura gastronómica.

Y que de la gastronomía mexicana desde su evolución histórica, y cómo ha impactado en cada región del país, todos sus platillos representativos que muestran la cultura de México, la opinión de algunos de los principales Chefs internacionales de cómo la consideran ante el mundo, la representación de la gastronomía mexicana y la forma de cómo rebasan las fronteras para darse a conocer por medio del uso de la fotografía, la aplicación del diseño gráfico y la representación de las mismas en la Web.

La importancia de la aplicación de los elementos mencionados anteriormente, se presenta por medio de un análisis visual de aquellas variables de la presentación de la gastronomía en la Web como, las formas y su composición de las fotografías que se usen en las mismas. Estas imágenes podrán ser vistas por millones de personas con el interés de conocer la gastronomía mexicana en donde en ocasiones persuada al espectador y genere la intención de conocer México y sus diferentes ciudades, atravesando las fronteras visualmente y porque no la intención de acudir a sus bellos lugares y probar nuestra gastronomía. 


\section{Gastronomía}

La literatura sobre gastronomía coincide en definirla como el estudio de la interacción de las colectividades humanas con sus alimentos. En este sentido Mascarenhas y Gándara (2010) señalan que "las prácticas alimentarias están cargadas de significados. Desde la elección de qué es o no comestible hasta en el modo de prepararlo, servirlo y consumirlo se pueden apreciar las características alimentarias vinculadas con la cultura y la sociedad" (p. 778). Mientras, Muñoz, Tamayo y Hernández (2012), mencionan que “de manera cultural, la gastronomía aporta una identidad mediante la representación de su historia en el platillo que se consume" (p. 5). Además, Gutiérrez (2012) afirma que "la gastronomía es la relación entre cultura y alimento" (p. 6).

En otro tema, la manera de conseguir los alimentos es a través de los sectores agrícola, ganadero, comercial e industrial (Gutiérrez, 2012). En el mismo tenor, se reconoce que la apropiación del suelo y las tecnologías agrícolas involucradas, también contribuyen a la obtención de los insumos gastronómicos Mascarenhas y Gándara (2010). Por otra parte, "en la gastronomía se debe tener un respeto profundo hacia a la naturaleza, haciendo uso eficiente de los recursos naturales que tienen a su alcance" (Muñoz, Tamayo y Hernández, 2012, p. 5).

Cuando la gastronomía se lleva a un nivel profesional, se apoya en distintas disciplinas para comprender el origen y la transformación evolutiva de los alimentos a través de la historia; para sistematizar los procesos sociales, culturales y económicos involucrados en la conformación de la gastronomía de una localidad; para analizar y mejorar la composición nutricional y los procedimientos de elaboración de los platillos (Gutiérrez, 2012).

\section{Historia e impacto de la gastronomía en la cultura mexicana}

Para hablar de la gastronomía en la cultura mexicana, habría que enmarcarla en el contexto de lo que se conoce como Mesoamérica y de los eventos históricos que compartieron las poblaciones indígenas que la habitaron. Una de las características principales de las culturas prehispánicas era que se habían originado al margen de las europeas, por lo que tuvieron un desarrollo civilizatorio primigenio y endógeno (García, 2011). La cultura gastronómica en México se originó y consolidó gracias a establecimiento de los grupos sedentarios porque los grupos nómadas, seminómadas carecían de los medios y de los conocimientos adecuados como para generar una gastronomía, ya que su alimentación estaba a merced de las circunstancias de estos grupos humanos (Verti, 1994).

Fue en el proceso de conquista y de colonización de Mesoamérica cuando la gastronomía local toma un significado importante por la valoración introspectiva de lo que era propio de las comunidades indígenas, frente a la de los conquistadores, aparte de la imposición de ciertos elementos culturales, incluyendo lo que respecta a lo culinario, y que fueron asumidos de una u otra manera en las distintas regiones.

Sin embargo, habría que resaltar la aportación de Mesoamérica en la gastronomía mundial, a través de la transportación de ingredientes como el cacao, el tomate, el aguacate, el 
frijol, el maíz, el chile, entre otros, llevados a Europa, a través de España; así como de la introducción de ingredientes como los aceites, azúcares, lácteos, harinas, etc., los cuales fueron incluidos en la gastronomía local, junto con las técnicas de cocina y el uso de utensilios y herramientas traídos de España (Verti, 1994). También en este mismo sentido el autor refiere que se trató de una relación simbiótica, gracias a que dicha tradición estuvo abierta y receptiva por lo que se complementó la gastronomía mesoamericana sin abandonar la base alimenticia local (Verti, 1994).

Se puede agregar que la base alimenticia de los mexicanos consistía y aún se basa en el maíz, el chile y el frijol, y conservando todavía los utensilios y herramientas prehispánicas como el comal, el molcajete, el metate, las ollas de barro, así como el procedimiento de nixtamalización (Audiffred, 2012). Por lo anterior, desde entonces, la cultura regional ha tenido un fuerte impacto en la gastronomía mexicana, propiamente, tanto por procesos que son meramente locales como por otros que han tenido alcances globales.

Uno de los elementos físicos que desde la época prehispánica ha tenido una dinámica social muy intensa es el tianguis o, por extensión, el mercado o centro de abastos, que es el lugar donde se distribuyen o intercambian los productos del campo-muchas veces de manera directa, sin intermediarios-. En el mercado se encuentran, además de los ingredientes básicos -maíz, chile y frijol-, la carne, las verduras, las frutas y las flores que son los insumos para la preparación de los alimentos que conforman la gastronomía mexicana (Audiffred, 2012).

Asimismo, el mercado es el espacio donde ocurren no sólo interacciones de compra-venta o de trueque, sino también de intercambio de información y de conocimientos, aunque no de manera generalizada. Y, donde se concreta esta información y estos conocimientos es, desde luego, en el hogar, entendido materialmente como el sitio donde se cocina, esto es, el fogón, que en muchas casas mexicanas está muy próximo al lugar donde se come; en este sentido, el autor le otorga un valor importante al acto de cocinar porque promueve la vida familiar y comunitaria, porque así se transmiten las recetas de generación en generación y se preservan las tradiciones gastronómicas (Audiffred, 2012).

Por otro lado, los procesos migratorios han ayudado a fortalecer en buena medida las estructuras sociales y a enriquecer la gastronomía local, porque contribuyen a la continuidad de los factores culturales -ingredientes, procedimientos, técnicas, idiosincrasia- en el contexto local. Aunque también se trata de un fenómeno que afecta cuando genera una ruptura de dichos factores culturales por la asimilación de los elementos de otra cultura; por ejemplo, la de la fast food, proveniente de los Estados Unidos.

Pero, de hecho, la migración ha permitido el ingreso de la gastronomía mexicana en dicho país y en todo el mundo, debido también al turismo; de tal manera que la gastronomía mexicana ha logrado un alcance importante a nivel internacional, al grado de obtener a fines de 2010 el reconocimiento como Patrimonio Inmaterial de la Humanidad, por la UNESCO (De'Angeli, 2003).

De acuerdo a lo anterior, se plantea realizar un análisis sobre el alcance de la gastronomía mexicana en otras latitudes, por medio de la fotografía y del uso de la tecnología; la Web, en este caso. Razón por la cual, el uso apropiado de la tecnología, a partir del diseño gráfico, permitirá la confluencia de los factores antes abordados. 
Por ello, es importante tomar como punto de partida a la cultura como "algo vivo, compuesta tanto por elementos heredados del pasado como por influencias exteriores adoptadas y novedades inventadas localmente" (Verhelst, 1994; citado en Molano, 2007, p. 72), que contemple las dimensiones y funciones sociales de la cultura: "un modo de vivir, cohesión social, creación de riqueza y empleo, equilibrio territorial” (Molano, 2007, p. 72). En todo caso, la cultura gastronómica tendría que ser entendida, en este tenor, como la acción humana de cocinar y de comer, que expresa los significados y los motivos, y que representa "el alcance y aprovechamiento de los recursos naturales existentes en su mismo espacio, así como las tradiciones heredadas por la familia en particular, y la sociedad en general" (Ochoa \& Santamaría, s.f., p. 152).

\section{El Diseño Gráfico en la Web}

La aplicación del diseño gráfico se encuentra también ya por varios años en la Web, perfeccionándose cada vez más, en donde también ha evolucionado significativamente por el impacto del Internet y la función que representa éste, siendo un buscador de todo tipo de temas, por lo que la adecuada aplicación del diseño gráfico y la fotografía en los diferentes sitios cubre diversas funciones, donde algunas de ellas informan, educan y logran persuadir por medio de sus imágenes traspasando fronteras, así sucede con la gastronomía mexicana.

Proenza (1999) describe el diseño gráfico como una "unidad destinada a ser puesta a la vista de un público al que debe transmitir un mensaje prefijado" (p. 137), esto es exactamente lo que sucede con el Internet, se exponen imágenes para transmitir diversas sensaciones, y pensando en los alimentos, podría ser el deseo por probarlos. Para complementar dicha definición Proenza (1999) agrega que "el universo del diseño gráfico es el área de comunicación mediante mensajes visuales lo que constituye el conjunto de comunicaciones funcionales, que comprende la institucional, la comercial, la publicitaria, la informativa, la didáctica, la señalética y la de identidad" (p. 137).

Para reforzar lo antes descrito, el mostrar la comida tradicional mexicana al mundo es con el afán de comunicar por medio de las diversas funciones del diseño gráfico, todo depende de la intención de la publicación y esto debe ser generado por un profesional de diseño gráfico.

Actualmente, el diseño se encuentra constantemente al alcance de los individuos, estando siempre bajo un objetivo, por ello debe cumplir su función y debe existir un procedimiento para la realización del mismo, por ejemplo desde la elaboración de un vaso para el agua hasta la realización de un espectacular de la calle, deben estar estratégicamente planeados para cubrir una función tangible e intangible, racional y emocional, que forma parte del contexto de un lugar bajo una intención, como lo explica Costa (2014):

En este sentido, el diseño es una actividad mediadora que tiene mucho que ver con la configuración del entorno artificial y constituye un elemento significativo de sus interacciones con los individuos y la sociedad. En la medida que la 
esencia del diseño es el impulso proyectual y creativo orientado hacia un fin determinado, su influencia en nuestros actos, nuestra mente y nuestra conducta puede llevarnos a lo mejor y a lo peor. A la mejora de nuestro hábitat, a la resolución de problemas y a la mayor calidad de vida. O bien a la manipulación y al control social. El diseñador gráfico es el responsable de la puesta en forma visual del mundo (p. 89).

El diseño como actividad mediadora entre el emisor y el receptor lleva a cabo diferentes funciones, por lo que actualmente se han recortado distancias ya que a través del Internet se puede acercar y observar de distintas esferas lo relacionado a la cultura y costumbres mexicanas, es decir, se rebasan las fronteras por medio de la Web.

Traspasar los límites por medio ésta, en la representación de la gastronomía es sumamente importante e indispensable, ya que es una manera de mostrar la cultura y con ella promover al turista en venir a nuestro país para degustar nuestra comida, lo cual es importante conocer el término frontera que describe Sánchez (2015):

El concepto frontera tiene dos dimensiones: la primera es aquella en la que frontera se refiere más a una zona desconocida y/o inexplorada no dominada y de potencial expansión. En este aspecto, la frontera trasciende los aspectos del límite, ya que no se trata de una "línea" delimitada que marca concretamente el fin y principio territorial, sino que, por el contrario, es un fin y principio de forma difusa, donde el límite no se concibe como presente, sino que existe la idea de que pudiera estarlo más allá en algún lugar de la frontera (p. 177).

En el Diseño Gráfico se deben considerar los fundamentos del diseño, en el que se tomarán en cuenta los elementos visuales, que es la jerarquización de los elementos en la fotografía, esto para lograr un equilibrio visual o focalizar el objetivo de dicha imagen, o simplemente el equilibrio de la composición. La jerarquización es la organización de elementos en donde a estos se les asigna importancia y cómo los mismos elementos se relacionan entre sí, son diferentes las técnicas para lograr la jerarquización visual como: la forma, tamaño, contraste, color, proximidad, alineación y repetición, si se le da más peso a una elemento este se hace más importante siendo más atraído visualmente por el receptor, en donde se cubre el objetivo posible del diseñador o fotógrafo.

En el análisis fotográfico se consideraron los fundamentos del diseño, analizar qué elemento capta la atención más rápidamente y con más claridad, en qué parte de la misma se focaliza el objetivo, ejemplo: Si hablamos del pozole y el tamaño más representativo lo tiene un limón, se perderá el objetivo de observar el elemento más importante, el plato con el pozole, por lo cual se pierde el objetivo de observar prioritariamente el elemento principal, y si todos fueran del mismo tamaño de igual manera se pierde el objetivo, existiendo solo equilibrio en la composición.

Cabe aclarar que los elementos de los fundamentos del diseño, de ser necesario se combinan, de tal manera que se busque un objetivo visual y que el receptor logre decodificar e identificar el propósito, siempre cuidando la estética y la realidad de la imagen fotográfica. 


\section{Páginas Web}

Al traspasar fronteras por medio de la Web, el interesado recurre a realizar una indagación de aquello que le interesa conocer y observar. Se identifica que su denominación es: www o Web, cuyos dominios se encuentran organizados por una serie de servidores a nivel mundial, se puede entender que se utilizan nombres asociados a instituciones o empresas, que son otorgados por empresas registradoras oficiales.

Se debe iniciar definiendo los objetivos que ha de cumplir la página Web, es decir: la referencia de datos de la empresa o de los productos a promocionar en Internet, la imagen de la empresa y/comercio y su marca, ya que si promociona a los productos es para provocar incremento en las ventas o dar a conocer algún tema, en el caso planteado la gastronomía mexicana.

Se identifican elementos donde la página Web Empresa (2019) consultada señala a cuatro modelos de negocios más habituales: Web Corporativa, e-Branding, e-Promotion, así como e-Commerce.

Una vez que se haya definido el modelo de Web, se procederá a diseñar la arquitectura, donde elementos como el diseño de interfaz de la Web, y es aquí en donde se abordan distintas áreas como el diseño gráfico, la usabilidad, la experiencia de usuario, la interacción, los mapas de sitio, así como términos como HTML, CSS, DOM, Javascript, AJAX, estándares Web y más; el diseño de la implementación o lógica de la aplicación, se denomina al procesamiento de datos, diseño o ejecución de algoritmos, manipulación de la información, es decir el planear aquello que se denominará en lenguajes de programación, y por último la arquitectura de la información, es decir la naturaleza de la información, modelo de datos y el motor de base de datos.

Se deben considerar los siguientes aspectos:

a. Accesibilidad en la Web, cuando una página de un producto o servicio Web puede ser accedido y usado por el mayor número posible de personas.

b. El diseño Web, considerar los siguientes 8 elementos que toda página ha de contener tal y como lo señala la página Web de VirtualiaNet (2018):

1. Contenido. Una página Web debe ser atractiva.

2. Tipografía. Es importante usar fuentes llamativas pero sencillas de leer.

3. Imágenes.

4. Animaciones y movimiento.

5. Botones e iconos.

6. Fondos claros y sencillos.

7. Enlaces a redes.

8. Sobriedad (s/p).

c. Para los portales Web es fundamental tener presente que contengan elementos que interactúan, esto facilitando la comunicación real entre la información y los usuarios, por lo tanto, debe contar con elementos que permitan que el usuario obtenga respuesta a cada acción. 
Con la finalidad de recoger información que permita validar de forma objetiva el presente tema, en donde lo característico del análisis y su complejidad es la observación e interpretación de un texto o imagen que lleve a ser interpretado, es decir, que con esto antes mencionado se busca expresar lo que el autor pretende transmitir, identificar dentro de un muestreo a elementos de análisis y de comparación que nos den valores de interpretación. Para lograr esto es necesario definir indicadores cualitativos que permitan analizar el contenido del material que se ha seleccionado. Se sistematiza a través de la localización de los elementos a analizar, se elabora una comparativa, para que estos datos permiten analizar partiendo de palabras claves -textual o no textual-, y donde a través del signo se logre definir su significado.

Esto se logra a través de unidades de muestreo y unidad de contexto que se codifica en relación al área observada cuyo caso aquí mostrado es la gastronomía mexicana en la Web, basándose en elementos como: presencia o ausencia de elementos, de orden, uso del color, proporción de la imagen y la fotografía.

Lo antes planteado, son los elementos que deben considerarse para la generación de una página Web y que además deben incorporar los criterios de diseño gráfico para impulsar la difusión y promoción de la gastronomía mexicana, pero al indagar en Internet, no se encontraron páginas Web especializadas que aborden esta temática y que hayan cumplido con los lineamientos del diseño que la literatura recomienda. Sin embargo, es relevante continuar con el análisis a través de fotografías sobre gastronomía mexicana localizadas mediante los buscadores más visitados en el 2019.

\section{La fotografía}

El análisis del contenido que se muestra en la Figura 1, se observa los niveles interpretativos de un contenido y las influencias sobre dicha escala.

Para el autor Andréu (1998):

En el nivel 1 microscópico-objetivo se intenta averiguar las posibles influencias de los indicadores estructurales, económicos, demográficos, etc. Sobre dicha escala de aspiraciones. En el nivel 2, el mundo macroscópico-subjetivo, la influencia de los medios de comunicación de masas. El nivel 3 la influencia de la opinión de los individuos sobre las circunstancias objetivas de una situación dada en un periodo dado. Y por último, en el nivel 4 la influencia de la opinión de los individuos sobre su propia realidad (p. 12). 
Figura 1. Las técnicas de Análisis de contenido. Andreu, (1998, pág. 31)

\section{MABROSEOṔPCO}
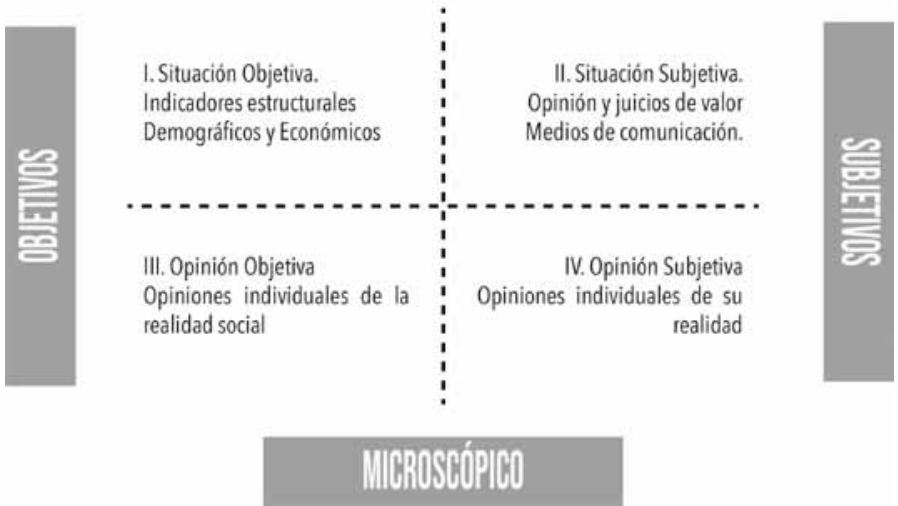

Figura 1. Las técnicas de análisis de contenido (Andreu, 1998, p. 31).

Al hablar de una imagen informativa como lo es la fotografía, se debe considerar un aspectos importantes: la interpretación de la imagen, donde se debe observar el contenido que ofrece y lo que representa; su conformación y la ilustración fotográfica, por lo que la fotografía se ha considerado como un elemento visual importante en el presente documento, ya que su función es de comunicación y representación, para manifestar la idea de aquello que se requiere expresar, es decir una imagen informativa. Donde los elementos de la imagen se consideran, según Santiago (2006) como elementos morfológicos: forma, relación figura-fondo, proporción, espacio, planos, luz.

\section{Principales sitios Web}

Para conformar este apartado, primero se buscó en Internet los sitios Web más visitados a nivel mundial en el 2019 y de acuerdo a los resultados que publica (a)Alexa Internet, Inc., se seleccionaron los diez buscadores más populares con el propósito de conocer la representación de la gastronomía mexicana en los referidos sitios.

Cabe mencionar que (a)Alexa es una compañía de Amazon.com que ofrece herramientas para perfeccionar las estrategias de SEO -search engine optimization o posicionamiento en buscadores- y PPC -pay per click o pago por click-, que permiten verificar el éxito y encontrar nuevas opciones para elevar las visitas en las páginas Web. Se utiliza principalmente por directores de marketing para llevar a cabo estrategias de mercadeo, por 
los equipos de liderazgo para elaborar diagnósticos y evaluaciones comparativas con la competencia, por los profesionales de negocios para invertir en empresas o productos y por los editores para verificar la popularidad y el éxito del sitio Web (Alexa, 1996-2019a). Según los estudios de la empresa (a)Alexa los sitios Web más visitados en el 2019, al día 17 de agosto, están en el siguiente orden: Google, YouTube, Facebook, Baidu, Wikipedia, Qq, Tmall, Yahoo, Taobao y Amazon. Al analizar los sitios referidos, se detectó que en Qq, Tmall $y$ Taobao son de origen chino y no se encontraron fotografías de la comida tradicional mexicana. El navegador $Q q$ se caracteriza por brindar una extensa diversidad de servicios a usuarios orientales; la plataforma Web Tmall se distingue por ofrecer a consumidores chinos productos de alta calidad del mercado global y el buscador Taobao se identifica por ser el más utilizado por los chinos para sus compras en línea -ranking páginas Web, 2019). Alexa (1996-2019b), describe los sitios Web seleccionados como:

- Google: permite a los usuarios buscar información del mundo, incluidas páginas Web, imágenes y videos. Ofrece Características únicas y tecnología de búsqueda.

- YouTube: es un sitio Web en el que se cargan, etiquetan y comparten videos en todo el mundo.

- Facebook: es una utilidad social que conecta a las personas, permite subir fotos, compartir enlaces y videos.

- Baidu: es un motor de búsqueda líder en China que ofrece una búsqueda simple y confiable.

- Wikipedia: es una enciclopedia gratuita creada en colaboración con el software wiki.

- Yahoo: es un importante portal de Internet y proveedor de servicios que ofrece resultados de búsqueda, contenido personalizable, salas de chat, correo electrónico gratuito, clubes y busca personas (s/p).

Para el presente estudio, sólo se seleccionaron y analizaron las fotografías de los primeros seis buscadores del ranking, exceptuando las páginas Web de Qq y Tmall. A criterio de las autoras se eligió la fotografía del alimento más representativo de la cultura gastronómica mexicana, que permitiera aplicar los parámetros establecidos en el "Análisis sobre las fotografías de platillos mexicanos” (García, Gutiérrez, Osuna, 2019, s/p).

\section{Análisis sobre las fotografías de platillos mexicanos}

A continuación se presenta el análisis de las fotografías de los platillos de comida tradicional mexicana que han sido seleccionadas según los criterios antes mencionados y se establecen los parámetros para el análisis, donde a la composición habrá de observarse desde lo armónico y los elementos en ésta. Es el significado el que se especifica para determinar el origen del platillo. Además, se observa el manejo del foco de atención de la fotografía y se genera una opinión objetiva y subjetiva del platillo desde el punto de vista de las autoras. 


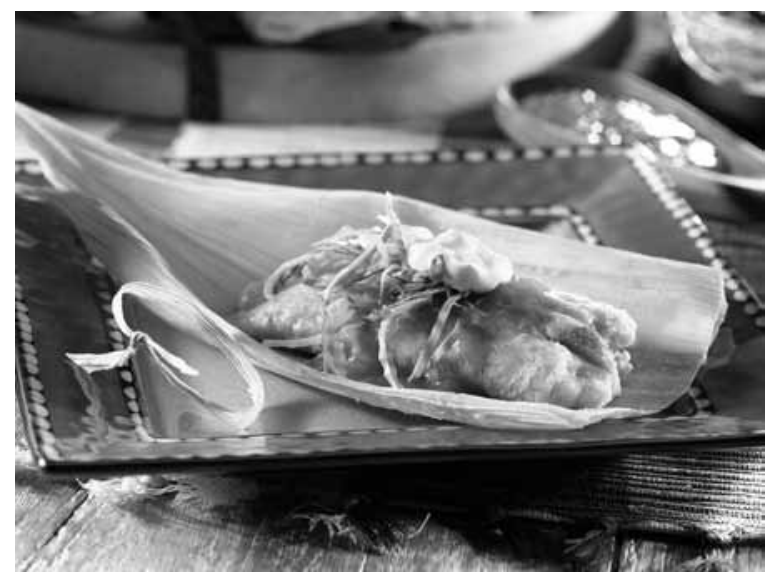

Figura 2. Tamal, platillo tradicional de la Cd. de México (Goya Foods, Inc., $2019, \mathrm{~s} / \mathrm{p})$.

En el ranking, la página más visitadas fue Google. En la búsqueda de los platillos tradicionales, se elige la fotografía de platillo tamal (Ver Figura 2). Proviene de nombre náhuatl tamalli que significa un envuelto que es preparado de masa de maíz, originalmente va envuelto en hojas de mazorca o de plátano (Tamales, s.f.). La fotografía muestra el aspecto principal elemento -tamal-, focalizado en relación al cuadrante de la imagen, donde el uso de la luz es aplicada de manera frontal hacia al objeto, la composición es armónica y central, dando prioridad a la visualización del tamal: dominante el tamal, subdominante el plato y subordinado: el resto del contexto, la relación del entorno muy ligero. En opinión objetiva la imagen describe el tamal, pero se considera que debería de visualizarse de un mayor tamaño el objeto a mostrar, y como opinión subjetiva se percibe que se antoja probarlo, se deduce el sabor salado de pollo y los elementos extra que muestra son -lechuga con crema-.

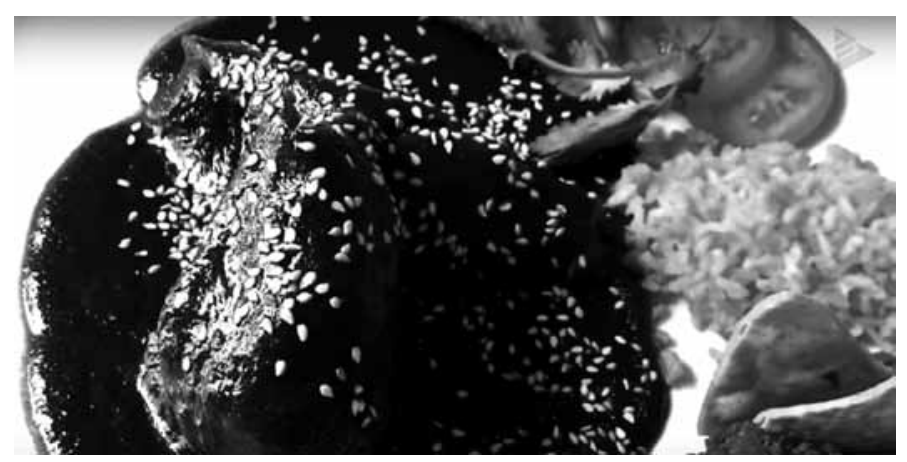

Figura 3. Mole, platillo típico de Cd. de Puebla (BakanoTV, 2017, 2'57') 
$\mathrm{Al}$ identificar YouTube como el segundo lugar de la Web más visitada, se determina elegir la fotografía cuyo nombre del platillo es mole poblano, mulli que significa mezcla, de origen prehispánico usado por los aztecas (Ver Figura 3). Es el más popular, cuya versión proviene del convento de Santa Rosa S. XVII Cd. de Puebla (Directo, 2017). La fotografía se encuentra focalizada en el contenido, dando importancia al producto elaborado. Se centra el objetivo en el mole -dominante-, en relación a los acompañamientos que son la sopa de arroz roja -subdominante-, y rodajas de jitomate y perejil -subordinado-. En opinión objetiva se percibe el contenido ampliamente; y como opinión subjetiva se identifica que cuenta con calidad de presentación, aspecto interesante del platillo y se antoja comerlo.

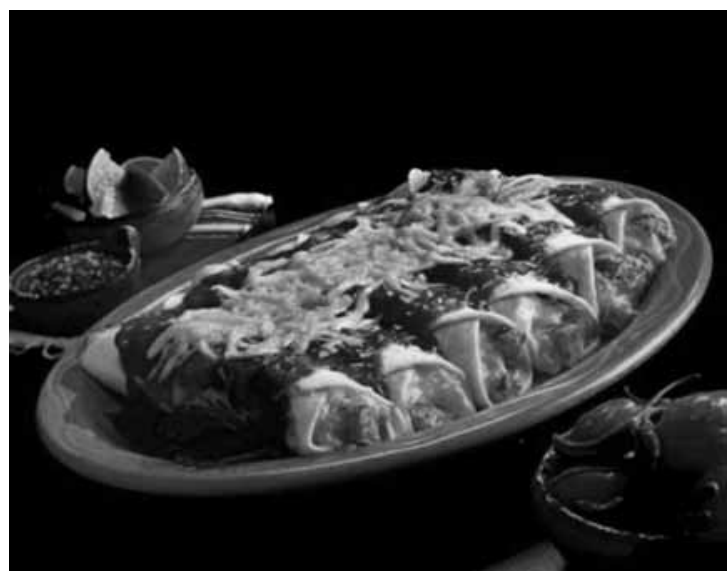

Figura 4. Enchiladas, platillo típico de México (Enchiladas, 2009, s/p).

El tercer lugar más visitado es Facebook, se selecciona la enchiladas, platillo cuya palabra náhuatl es chilli y tlapitzalli que significa flauta, flauta enchilada (Enchilada, 2015) (Ver Figura 4). La toma de la fotografía está centrada, la forma ovalada del plato permite que se equilibre visualmente la organización de la repetición en secuencia de la forma de las enchiladas. Esa técnica cuyo aspecto principal es la forma que genera la composición basada en el acomodo de la forma de las enchiladas -dominante-, en relación al plato -subdominante-, y la ambientación poco visible -subordinado-, fotografía visualmente armónica. La opinión objetiva describe los contenidos físicos de una enchilada pues se observa la salsa y la tortilla, complementa al dejar ver el relleno de la enchilada, una forma muy original de presentar el platillo y que subjetivamente por la secuencia genera la idea de un platillo delicioso, enchilado y apetitoso. 


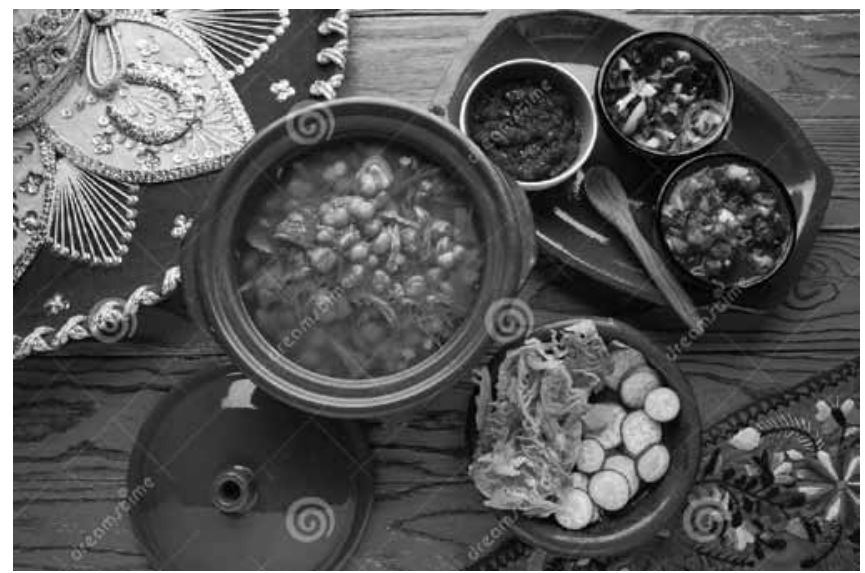

Figura 5. Pozole platillo tradicional de Guerrero (Lunamarina, 2000-2019, s/p).

Para el análisis de la Figura 5, se localizó en la página Web de Baidu, el platillo náhuatl que originalmente se escribe pozolli que significa espuma, hecho a base de maíz de granos grandes blancos llamados cacahuazintle (Yalina, 2014). El mensaje visual en la jerarquización de los elementos, no muestra como contenido principal al pozole y que con los demás elementos -los acompañamientos-, no genera un equilibrio visual. Describe la organización de elementos basados en un desequilibrio formal ya que el pozole se encuentra en posición subdominante y no dominante como se pensaría que debería de ser, aun cuando la posición visual si se encuentra de forma jerárquica marcada por la altura del plato del pozole, aquí el dominante se confunde con el subdominante, pero si se visualiza al subordinado - plato de rábanos y lechuga-. En opinión objetiva se identifica un poco de ruido visual, ya que se encuentran elementos como el sombrero y el bordado que generan un ambiente mexicano -tapatío- y como opinión subjetiva se aprecia una comida apetitosa y se antoja.

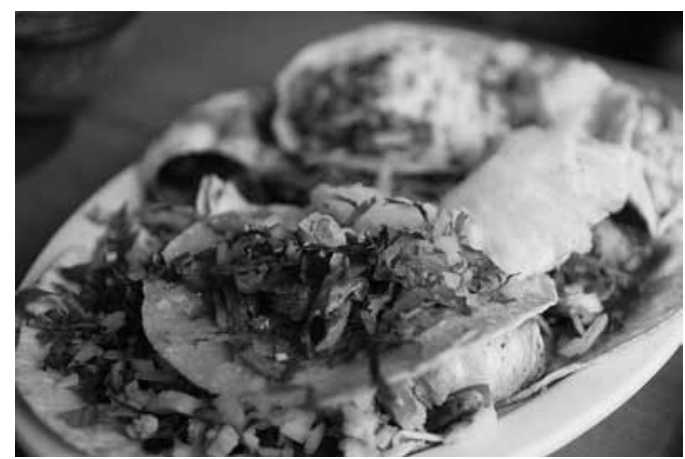

Figura 6. Tacos al pastor. Versión mexicana de platillos de oriente (Neuheisel, 2009, s/p). 
Al visitar la página de Wikipedia, se localiza al platillo tradicional de tacos al pastor (Ver Figura 6), denominados así por su estructura en el uso de la tortilla, tacos al pastor que también reciben el nombre de tacos de trompo o adobada, existe la versión que provienen del Líbano shawarma, de Grecia gyros o de Turquía kebab (El Siglo, 2012). En la foto se muestra como una propuesta no armónica en contenido, pero representa la forma usual del sujeto, no está bien hecha la imagen para significar claramente al receptor. En composición se percibe desorganizada, presenta prioritariamente sólo un taco al pastor, dejando desenfocados los otros tacos que bien pudieran generar armonía, hecho que no permite identificar al dominante, subdominante y subordinado. La opinión objetiva es que sí da significado a la presencia del contenido, pero se percibe muy limitada su expresión visual y subjetivamente la fotografía genera la idea del taco al pastor, pero no se antoja al verlo precisamente por el desenfoque del resto del contenido.

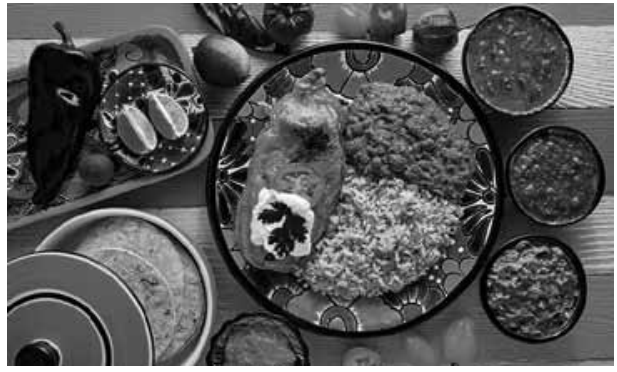

Figura 7. Chile relleno plato tradicional de la Cd. de Puebla (Lunamarina, $2016, \mathrm{~s} / \mathrm{p})$.

Al visitar la Web Yahoo, se visualiza el platillo tradicional denominado chiles rellenos (Ver Figura 7). Sus orígenes se remontan a la conquista española de México en el siglo XVI, asumiendo una mezcla de productos indígenas y españoles (Clark, 2017). En el uso de la imagen fotográfica se observa la falta de armonía visual, carente de equilibrio, existe saturación de la forma con significantes no definidos. La composición muestra una saturación visual de elementos, donde no se percibe claramente el chile relleno, que junto con los frijoles y la sopa de arroz son el dominante, el subdominante es el tortillero y subordinado las tres salseras. Como opinión objetiva genera confusión, porque no se logra la expresión del mensaje de un chile relleno pues existen demasiados elementos en la composición, subjetivamente el observador se puede confundir porque no se visualiza claramente el objetivo a mostrar, ya que existen otros alimentos que sirven de acompañamiento al elemento principal -el chile-, más no declara el elemento a comunicar. 


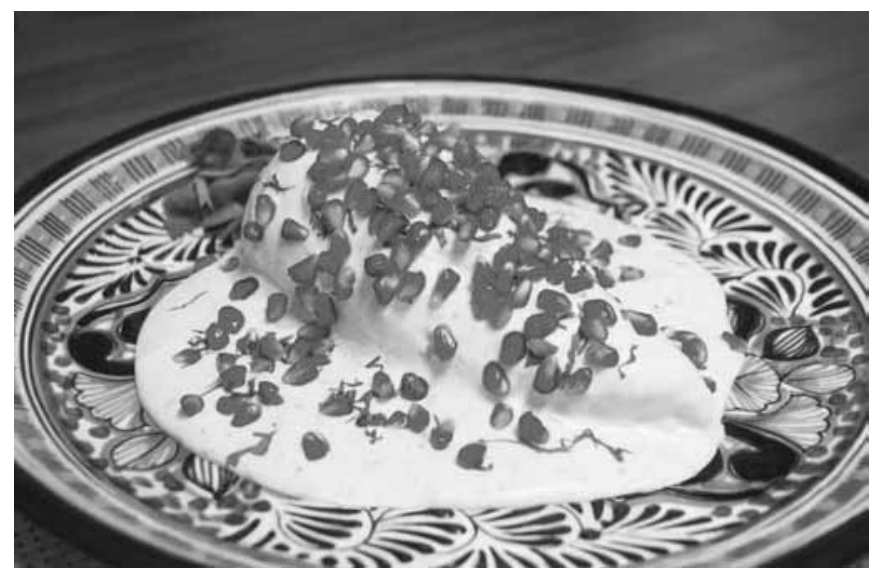

Figura 8. Chile en Nogada, platillo típico de Puebla (Chile en nogada, s/f.)

En el mismo buscador de Yahoo también se localizó el platillo de chiles en nogada (Ver Figura 8), denominado así porque la salsa de nuez de crema lleva la palabra nogal que en español significa árbol de nuez; existe la versión de que su origen es de San Agustín, en Puebla y el platillo especial fue elaborado por monjas de un convento local (Clark, 2017). El uso de la imagen fotográfica muestra al significante dando el mensaje intencional, se identifica el componente principal en primer plano, por lo tanto la composición visual es armónica destacando el chile en nogada, dominante el plato con el producto a mostrar. Opinión objetiva se describe clara y contundente al elemento, al no mostrar ambientación se dice que la fotografía es simple pero sí cumple la función. Desde lo subjetivo genera el antojo por consumir y detectar ese sabor de la crema y la nuez así como la combinación de la granada -dado que las fotografías se identificaron a color, solo se describe su función-.

\section{Valoración de la gastronomía mexicana}

Las valoraciones de chefs internacionales respecto a la gastronomía mexicana se incorporan con el propósito de evidenciar que ésta rebasa fronteras en el mundo y adicionalmente se le reconoce como patrimonio inmaterial de la Humanidad por parte de la UNESCO, reconocimiento otorgado para proteger los métodos tradicionales de elaboración y celebrar la contribución de México a la cocina universal.

Otro aspectos a considerar es que la gastronomía mexicana traspasa fronteras de forma significativa, por su historia, diversidad de ingredientes, técnicas, por su sabor, color, textura, aroma y los aportes nutricionales, por lo que cada día existen más restaurantes de comida mexicana en otras fronteras con una gran connotación e impacto en la sociedad. Los siguientes tres profesionales de la cocina plasman una importante opinión sobre la gastronomía mexicana: 
Anthony Bourdain, chef estadounidense con reconocimiento internacional, falleció el 8 de junio de 2018, él afirmó tener conocimiento sobre la comida mexicana y expresó "que encontraba muy injusto que nuestra comida estuviera aún estereotipada como fritanga barata, pues la comida mexicana va más allá de los tacos o los burritos" (TKM, 2016, s/p).

El mismo Bourdain, expuso:

Me gustaría que la gente le prestará más atención a la cocina mexicana de alta calidad, creo que está infravalorada y en el mundo de la gastronomía no es apreciada como debería. Por ejemplo, hay muchos casos en los que la elaboración de los platillos data de hace siglos, y que además tiene una increíble cantidad de sabores, como por ejemplo el caso de las salsas de Oaxaca, estado en el que las recetas datan desde mucho antes que Europa (TKM, 2016, s/p).

Fabio Bernardini, chef de origen brasileño, fue "uno de los 10 diez finalistas de Latinoamérica en el concurso Young Chef que organiza la marca de agua con gas San Pellegrino, y uno de los cinco que representan a México" (Notimex, 2015, s/p). Bernardini en Notimex (2015), también señala que "el sabor de la cocina mexicana es difícil de borrar" (s/p) y por otra parte agrega "que en muchos lugares aún existe una interpretación errónea de la comida mexicana: La gente piensa que todo pica, que todo es demasiado condimentado y no es así, existe una infinita variedad de texturas y sabores" ( $\mathrm{s} / \mathrm{p})$.

Adicionalmente, detalló que el estado de Oaxaca lo cautivó, "los sabores de ese lugar no tienen parecido con ningún otro, la calidad de los productos, la mezcla de los mismos, hacen que la gente se inspire" (Notimex, 2015, s/p).

Yue Heng, chef de China, reconocido por el gobierno mexicano al otorgarle la condecoración Águila Azteca por sus aportes a la difusión de su gastronomía en Estados Unidos, en Beijing tiene un restaurante llamado Pebbles, centrado en la comida mexicana y donde se recuerda el colorido y estilo de México. Para lograr lo anterior, visitó "México para aprender en la cuna de una de las mejores cocinas del mundo, y porque además México y China son dos culturas antiguas que a lo largo del tiempo han compartido sabores y colores" (Sueño joven emprendedor, 2018, s/p). Yue Heng afirma lo siguiente:

Creo que para mí es más una pasión, que sólo hacer dinero, es por eso que fui tan lejos. Fui a México a hacer una investigación por mí mismo, esto comenzó a crecer desde que no sabía nada de comida. En este momento puedo decir que soy uno de los expertos en cocina mexicana en China. Además, agrega que "En China, muchos restaurantes de comida mexicana no están sirviendo realmente comida mexicana, todo es Tex-Mex. Es por eso que yo quiero llevar un sabor más auténtico a todo el país (Ávila, 2018, s/p).

Las diversas y enriquecedoras opiniones de estos profesionales chefs, dejan claro que la gastronomía mexicana tiene historia y una cultura percibida e identificada en los alimentos, las cuales atraviesan fronteras y son dignos de ser difundidos en las páginas Web, para 
con ello mostrar la cultura bajo la estética de las fotografías y persuadir al extranjero para venir a México con la intención de probar su gastronomía.

\section{Conclusiones}

Al establecer los parámetros para determinar cómo se podría seleccionar y valorar las imágenes de los alimentos desde el punto de vista del diseño gráfico, se llegó a la decisión de valorar los elementos de forma-función, considerando a la fotografía como parte importante.

En la búsqueda de la gastronomía mexicana en la Web se llega a concluir que no siempre se logra definir el diseño gráfico con la fotografía, pues en el análisis de éstas, se percibe saturación con elementos de forma y no se busca directamente la función de la fotografía. Y se agrega que las imágenes encontradas, algunas de ellas van dirigidas a alimentos de la alta cocina mexicana-gourmet-, dejando a un lado a la representación real de la gastronomía mexicana, disminuyendo la importancia del arte culinario en México, evitando con ello traspasar fronteras en la Web con lo más representativo culturalmente que para el presente estudio es la gastronomía en México.

Al considerar elegir los buscadores más visitados no todos fueron efectivos, pues en dos de ellas no se identificó información que hablarán de comida tradicional mexicana, además no se localizaron páginas Web que lograrán el propósito del planteamiento inicial de este documento.

Desde el diseño gráfico es importante la función comunicativa de la fotografía, del uso de ésta en la Web y sobre todo potencializar los esquemas para un mejor resultado del diseño. Posiblemente no siempre se recurre a la imagen fotográfica, pero sí es importante generar una transmisión correcta del significado que se desea comunicar. Mensaje que se forma desde el boceto, se interpreta con la imagen y se logra con la interpretación del individuo que lo recibe.

El recorrido del presente artículo permite aportar un poco de la expresión lograda con la fotografía como herramienta para el diseñador gráfico en la Web. Posiblemente queden algunos cabos sueltos de las imágenes, pero la intención marcada en el objetivo del presente se logra con un sencillo lenguaje, introspección a un pasado de la cultura mexicana y de las aplicaciones en la Web.

Por lo cual se considera que la gastronomía mexicana si traspasa fronteras, ya que en 6 de los 8 sitios Web que se observan, si se encuentra platillos representativos de México independientemente de su buena o mala representación gráfica y fotográfica.

\section{Referencias Bibliográficas}

Alexa Internet, Inc. (1996-2019a). Find Reach and Convert Your Audience. Recuperado de: https://www.alexa.com/ 
Alexa Internet, Inc. (1996-2019b). The top 500 sites on the web. Recuperado de: https:// www.alexa.com/topsites

Andréu Abela, J. (1998). Técnicas de análisis de contenido. Recuperado de: http://mastor. cl/blog/wp-content/uploads/2018/02/Andreu.-analisis-de-contenido.-34-pags-pdf.pdf

Audiffred, M. (2012). Cocina mexicana. Colección Marca América Latina. México, D.F.: Editorial Difusión.

Ávila, O. (23 de septiembre de 2018). Comida mexicana que seduce a China; el auténtico sabor... en Asia. Excelsior. Recuperado de: https://www.excelsior.com.mx/nacional/ comida-mexicana-que-seduce-a-china-el-autentico-sabor-en-asia/1266916

BakanoTV. (2017, octubre 14). Top 10 de Comida Mexicana (TOP 10) [Archivo de video]. Recuperado de: https://www.youtube.com/watch?v=WZdW59jDWtA

Chile en nogada [Fotografía]. (s.f.). Recuperado de: https://mx.images.search.yahoo. com/search/images;_ylt=AwrgEawm1WBdSSAAVijD8Qt.;_ylu=X3oDMTB0NjZjZz ZhBGNvbG8DZ3ExBHBvcwMxBHZ0aWQDBHNlYwNwaXZz?p=chiles+en+no gada $\&$ fr $2=$ piv-web $\&$ fr=yfp-t-s\#id=11\&iurl=http $\% 3 \mathrm{~A} \% 2 \mathrm{~F} \% 2 \mathrm{Fmx}$.emedemujer. com\%2Fwp-content $\% 2$ Fuploads\%2Fsites\%2F5\%2F2017\%2F08\%2FChile-en-Nogada-1. jpg\&action $=$ click

Clark, J. (20 de noviembre de 2017). La Historia de los chiles rellenos mexicanos. Recuperado de https://www.ehowenespanol.com/historia-chiles-rellenos-mexicanos-sobre_74543/

Costa, J. (2014). Diseño de Comunicación visual: el nuevo paradigma. Revista Gráfica, 2 (4). Universitat Autònoma de Barcelona, España.

De'Angeli, G. (2004). Continuidad y ruptura de las costumbres culinarias. Conferencia magistral. En Patrimonio cultural y turismo. Cuadernos $7.5^{\circ}$ Congreso sobre Patrimonio Gastronómico y Turismo Cultural. Puebla, 2003. Memorias. México, D.F.: CONACULTA.

Directo al paladar (30 de mayo de 2017). Recuperado de: https://www.directoalpaladar. com.mx/ingredientes-y-alimentos/el-mole-un-platillo-tradicional-lleno-de-historia

El Siglo de Durango (2012). “¿Por qué se llaman tacos al pastor?”. Recuperado de: https:// www.elsiglodedurango.com.mx/noticia/405034.por-que-se-llaman-tacos-al-pastor.html

Enchilada. (17 de Septiembre de 2015). Recuperado de: https://deliciasprehispanicas. com/2015/09/17/palabra-enchilada-y-su-origen-nahuat

Enchiladas [Fotografía]. (2009). Recuperado de https://www.facebook.com/86508943302/ photos/a.444076303302/86511408302/?type=1\&theater

García Colín Carrillo, D. (2011). Los pueblos prehispánicos en Mesoamérica. Recuperado de https://www.marxist.com/los-pueblos-prehispanicos-mesoamerica.htm

Goya Foods, Inc. (2019). Tamales Mexicanos de Chile y Queso. [Fotografía]. Recuperado de https://www.goya.com/media/3716/mexican-cheese-and-chile-tamales1.jpg?quality=80

Gutiérrez de Alva, C. I. (2012). Historia de la gastronomía. Estado de México: Red Tercer Milenio.

Lunamarina (2000-2019): Pozole with mote big corn stew from Mexico. Pepper, mexican. [Fotografía]. Recuperado de: https://thumbs.dreamstime.com/z/pozole\%E7\%94\%A8-\% Е5\%A2\%A8\%E8\%A5\%BF\%E5\%93\%A5\%Е7\%9A\%84\%E5\%BE\%AE\%E7\%B2\%92\%E 5\%A4\%A7\%E7\%8E\%89\%E7\%B1\%B3\%E7\%82\%96\%E7\%85\%AE\%E7\%9A\%84\%E9 \%A3\%9F\%E7\%89\%A9-66444706.jpg 
Lunamarina (2016). Chile relleno con queso. [Fotografía]. Recuperado de: https://st2. depositphotos.com/1053932/10727/i/950/depositphotos_107270560-stock-photo-chilirelleno-chili-peppers-filled.jpg

Mascarenhas Tramontin, R. G. \& Gândara Gonçalves, J. M. (2010). Producción y transformación territorial. La gastronomía como atractivo turístico. En Estudios y Perspectivas en Turismo, 19(5), septiembre-octubre, pp. 776-791. Centro de Investigaciones y Estudios Turísticos. Buenos Aires, Argentina. Recuperado de http://www.redalyc.org/ pdf/1807/180717609011.pdf

Molano L., O. L. (2007). Identidad cultural un concepto que evoluciona. Opera, (7), pp. 69-84. Universidad Externado de Colombia. Bogotá, Colombia. Recuperado de http:// www.redalyc.org/pdf/675/67500705.pdf

Muñoz Muñoz, I.; Tamayo Salcedo y A. L.; Hernández Heredia, C. (2012). Formación profesional de la gastronomía en instituciones públicas en México. Actualidades Investigativas en Educación, 12(3) (Septiembre-Noviembre), pp. 1-18. Universidad de Costa Rica San Pedro de Montes de Oca, Costa Rica. Recuperado de http://www.redalyc.org/ pdf/447/44723985008.pdf

Neuheisel, W. (2009). Tacos al pastor. [Fotografía]. Recuperado de: https://es.wikipedia. org/wiki/Taco_al_pastor\#/media/Archivo:01_Tacos_al_Pastor.jpg

Notimex (8 de febrero de 2015). La gastronomía mexicana, en el paladar del mundo. El Informador. Recuperado de https://www.informador.mx/Cultura/La-gastronomiamexicana-en-el-paladar-del-mundo-20150208-0042.html

Ochoa Leyva, K. \& Santamaría Gómez, A. (s.f.). Cultura gastronómica. Culinaria. Universidad Autónoma del Estado de México. Recuperado de http://web.uaemex.mx/Culinaria/ tres_ne/articulo_08.pdf

Proenza Segura, R. (1999). Diccionario de publicidad y diseño gráfico 3R Editores/Panamericana, Bogotá Colombia.

Ranking de las 10 páginas web más visitadas del mundo en 2019 (17 de agosto de 2019). ElectronicaHoy.es. Recuperado de https://electronicahoy.es/las-10-paginas-web-masvisitadas-del-mundo-2019/

Sánchez Ayala, L. (2015). De territorios, límites, bordes y fronteras: una conceptualización para abordar conflictos sociales. Revista de estudios sociales. Universidad de los Andes Colombia.

Santiago Barnés, J. (2006). ¿Qué son las imágenes? Interpretaciones y aplicaciones. Publicaciones Universidad Pontificia de Salamanca. Salamanca, España.

Sueño joven emprendedor (22 de agosto de 2018). Xinhua Español. Recuperado de http:// spanish.xinhuanet.com/photo/2018-08/22/c_137404252.htm?from=singlemessage\&is appinstalled $=0$

Tamales Emporio (s.f.). Recuperado de: https://www.tamales.com.mx/pages/el-tamal-ysus-origenes

TKM (27 de septiembre de 2016). "Esto es lo que Anthony Bourdain piensa de la comida mexicana”. TKM. Recuperado de: https://www.mundotkm.com/mx/comida/179629/ esto-es-lo-que-anthony-bourdain-piensa-de-la-comida-mexicana

Verhelst, T. (1994). Las funciones sociales de la cultura. Cultura y desarrollo rural. En LEADER Magazine $\mathrm{N}^{\circ} 8$.

Verti, S. (1994). Esplendor y grandeza de la cocina mexicana. México, D.F.: Editorial Diana. 
VirtualiaNet (2018). Recuperado de: https://blog.virtualianet.com/diseno-web-los-8-elementos-imprescindibles/

Web Empresa (2019). Recuperado de: (https://www.webempresa20.com/libro-online/253web-empresa-20-paso-1-estrategia-digital.html)

Yalina, M. (12 de septiembre de 2014). "Lo que seguramente no sabías del pozole". Recuperado de: https://www.mexicodestinos.com/blog/2014/09/lo-que-seguramente-nosabias-sobre-el-origen-del-pozole/

\begin{abstract}
Gastronomy is "the culinary art", where beyond the ingredients, techniques and methods of their recipes they bring with them the historical evolution and its cultural meaning of the region where the flavors, colors, ingredients, are something like the bond of being human with his diet. In Mexican culture is where we find a great variety of regional dishes that have been maintained over time, recipes from the pre-Hispanic era that are still in the town of Mexico, obviously with the passage of time modified, due to a lack of registration, but that does not mean that it loses its great cultural value, because on a global level we can hear about it. Imagine the scope of a food dish in its maximum digital graphic representation where through color, typography, shapes and photography and composition can be taken to different sites through the Internet, where thousands of people from all over the world world that surf the web, cross borders discovering the gastronomy of a region, taking with it not only the visual impact of the piece of design but showing the cultural richness of Mexico.
\end{abstract}

Keywords: Mexico - Graphic Design - Web - Culture - Borders.

Resumo: A cozinha é "arte culinária", onde além dos ingredientes, técnicas e métodos de suas receitas transportar a evolução histórica e significado cultural da região onde os sabores, cores, ingredientes, são algo como o vínculo de ser humano com sua dieta.

A cultura mexicana é onde encontramos uma variedade de prato regional que permaneceram ao longo do tempo, receitas tempos pré-hispânicos até hoje mantido na cidade do México, obviamente com a passagem do tempo tem modificado, devido à falta de registro, mas isso não significa que ele perde seu grande valor cultural, porque em um nível global podemos ouvir sobre isso. Imagine que o alcance que terá um pires de comida no seu melhor representação gráfica digital, onde através de cores, tipografia, formas e fotografia e composição podem levar a diferentes sites através da internet, onde milhares de pessoas em todo o mundo que navegar na web, vai atravessar fronteiras descobrindo a cozinha de uma região, trazendo não só o impacto visual da parte de design, mas mostrando a riqueza cultural do México.

Palavras chave: México - Design Gráfico - Web - Cultura - Fronteiras.

[Las traducciones de los abstracts fueron supervisadas por el autor de cada artículo] 